Research

\title{
Which urine marker test provides more diagnostic value in conjunction with standard cytology- ImmunoCyt/uCyt+ or Cytokeratin 20 expression
} Isin Soyuer*1, Mustafa Sofikerim ${ }^{\dagger 2}$, Fatma Tokat ${ }^{\dagger 1}$, Serdar Soyuer ${ }^{\dagger 3}$ and Figen Ozturk ${ }^{\dagger}$

Address: ${ }^{1}$ Pathology Department, Erciyes University, Medical Faculty, Kayseri, Turkey, ${ }^{2}$ Urology Department, Erciyes University, Medical Faculty, Kayseri, Turkey and ${ }^{3}$ Radiation Oncology Department, Erciyes University, Medical Faculty, Kayseri, Turkey

Email: Isin Soyuer* - isinsoy@erciyes.edu.tr; Mustafa Sofikerim - mustafasofikerim@yahoo.com; Fatma Tokat - drftokat@hotmail.com; Serdar Soyuer - soyuers@erciyes.edu.tr; Figen Ozturk - ozfigen@erciyes.edu.tr

* Corresponding author †Equal contributors

Published: 26 June 2009

Diagnostic Pathology 2009, 4:20 doi:10.1 I86/1746-1596-4-20
Received: 17 April 2009

Accepted: 26 June 2009

This article is available from: http://www.diagnosticpathology.org/content/4/I/20

(C) 2009 Soyuer et al; licensee BioMed Central Ltd.

This is an Open Access article distributed under the terms of the Creative Commons Attribution License (http://creativecommons.org/licenses/by/2.0), which permits unrestricted use, distribution, and reproduction in any medium, provided the original work is properly cited.

\begin{abstract}
Background: Because of the poor sensitivity of urinary cytological findings for the diagnosis of especially low grade urinary bladder carcinoma, new molecular diagnostic methods have been proposed. We decided to verify the ImmunoCyt/uCyt+ (UCyt+ $\left.{ }^{\mathrm{TM}}\right)$ test and cytology combination and cytokeratin 20 (CK20) and cytology combination in urine as possible diagnostic and monitoring tool for bladder cancer.
\end{abstract}

Methods: Evaluation of CK20 expression and UCyt+ ${ }^{\mathrm{TM}}$ was performed in urine of 90 patients of which 54 with bladder cancer with primary/recurrent diagnosis (low grade urothelial carcinoma $($ LGUC $)=23 / 8$ patients, high grade urothelial carcinoma $(\mathrm{HGUC})=18 / 5$ patients), and 36 patients as control; except of neoplastic bladder disease patients. For the evaluation of the three tests, $\mathrm{CK} 20$ and $\mathrm{UCyt}+{ }^{\mathrm{TM}}$ tests were combined with urine cytology and compared with each other.

Results: The overall sensitivity detected for each tumor marker was as follows: for urine cytology was $75.9 \%$ and $U \mathrm{Cyt}^{\mathrm{T}}{ }^{\mathrm{TM}}$ was $83.3 \%$, for CK20 $70.4 \%$, while the specificity was $66.7 \%$ for urine cytology and $86.1 \%$ for $\mathrm{UCyt}^{\mathrm{TM}}$ and $83.3 \%$ for CK20. The sensitivity of cytology and UCyt+ ${ }^{\mathrm{TM}}$ combination was higher $(88.9 \%)$ than the sensitivity cytology and CK20 combination (77.8\%). The simultaneous use of the three markers, sensitivity was reaching $92.5 \%$.

Conclusion: The UCyt ${ }^{\mathrm{TM}}$ test and CK20 expression are valid tools for the performance of adjunctive analyses with conventional cytologic examination.

\section{Background}

Bladder cancer is the second most common urologic cancer [1]. The majority of patients with newly diagnosed bladder cancers have superficial, low-grade neoplasms that are associated with an excellent prognosis. However, these tumors have a $30 \%$ to $70 \%$ recurrence rate and may progress to invasive cancers in $10 \%$ to $30 \%$ of patients; progression greatly increases the risk of metastasis and 
subsequent mortality $[2,3]$. For this reason, the early detection of bladder tumors is essential for improved patient prognosis and long-term survival.

Cytology is noninvasive and has high specificity but low sensitivity, especially for low-grade tumors. At the same time, it can be a challenging test to perform and is highly dependent on the skills and experience of a trained cytopathologist. Thus, published studies have reported a wide range of sensitivities (15.8\%-84.6\%) [4-12].

Because cystoscopy is invasive and because cytology has poor sensitivity, noninvasive biomarkers have been sought as alternatives to cystoscopy and cytology for the detection and surveillance of bladder cancer.

The ImmunoCyt/uCyt $+\left(\mathrm{UCyt}+{ }^{\mathrm{TM}}\right)$ test (Diagnocure) is an immunocytological fluorescence assay designed to improve the sensitivity of cytology. A cocktail of 3 monoclonal antibodies is used to detect antigens originating specifically from tumors of transitional epithelial cells. The M344 and LDQ10 antibodies are labeled with fluorescein, a green fluorescence, and will recognize a mucinlike antigen located in the urine on exfoliated tumor cells. The 19A211 antibody will recognize the presence of a high molecular weight glycosylated form of carcinoembrionic antigen and is labelled with Texas Red [13].

Still, this test, like cytology, remains subjective and depends in part on the technician. Observer experience, specimen stability and handling and differences in sample size may explain the variation in reported $\mathrm{UCyt}^{\mathrm{TM}}{ }^{\mathrm{TM}}$ sensitivity [6]. Because of this, we added another marker, cytokeratin 20 (CK 20) which is easily used in conjunction with cytology and comparable with cytology and $\mathrm{UCyt}+{ }^{\mathrm{TM}}$ test.

Cytokeratins are intermediate filaments expressed in epithelial cells [14]. One of these, cytokeratin 20, is expressed higher in urothelial tumors in comparison with normal transitional epithelium so it can be considered a marker of urothelial differentiation [14].

The aim of this study was to investigate the validity of the $\mathrm{UCyt}^{\mathrm{TM}}$ test and CK20 expression alone and in combination with conventional cytology for detecting bladder cancer.

\section{Methods}

This study was performed on 90 patients admitted to the Urology and Pathology Departments, Faculty of Medicine, Erciyes University Hospitals, Turkey. All patients provided a single voided urine sample, and cytological tests of the urine sediment were performed before cystoscopy. Cystoscopy was done for all patients as the reference standard for identification of bladder cancer. All tumors and suspicious lesions found were either resected or biopsied. The final diagnosis of bladder cancer was based on histopathological examination.

To exclude interference with inflammation or hematuria, none of the follow up urine samples was collected earlier than 3 months after TUR-B or 1 month after intravesical instillation.

For the cytologic examination 40 to $100 \mathrm{~mL}$ specimens of voided urine were collected. This material was immediately fixed with equal volumes of $50 \%$ ethanol and $1 \mathrm{~mL}$ of a special fixative solution. Samples were centrifuged at $2500 \mathrm{rpm}$ for 10 minutes. Cytospin preparations 294 $\mathrm{mm}^{2}$ in diameter were prepared on poly-L-lysine-coated slides. Slides were stained by a routine Papanicolaou method and performed microscopic examination. The slides were examined at $40 \times$ magnification.

All patients with superficial disease underwent transurethral resection of the bladder. Urothelial cancer grading and staging were performed according to the World Health Organization criteria [15].

On the cytologic examination, specimens were evaluated for adequacy; those with fewer than 10 urothelial cells were designated unsatisfactory and rejected. The primary interpretation for each cytology case was classified as benign or malignant by using previously published cytologic criteria for the diagnosis of carcinoma [16]. Specifically, the cytologic parameters evaluated included increased nuclear size elevated nuclear-to-cytoplasmic (N/ C) ratio, nuclear pleomorphism, hyperchromasia, nuclear eccentricity, nuclear membrane irregularity, and cytoplasmic homogeneity. When none or one of these was present, the diagnosis was rendered as "benign". When most or all were present, the case was diagnosed as "malignant". "Atypical or suspicious" cases were added to the malignant group, which had two or three of these parameters but were not sufficient for a "malignant" diagnosis. When calculating the sensitivity, specificity, positive and negative predictive values, the suspicious cases were considered as positive cases.

The $\mathrm{UCyt}^{\mathrm{TM}}$ is a commercially available immunocytological assay based upon microscopical detection of tumorassociated cellular antigens in urothelial cells by immunofluorescence (Diagnocure Inc., Quebec, Canada). The test was performed according to the manufacturer's protocol. Voided urine $(>30 \mathrm{ml})$ was prefixed with an equal amount of ethanol (50\%) and $0.5 \mathrm{ml}$ fixative solution. The samples were then stored at $4{ }^{\circ} \mathrm{C}$ for up to 7 days. Slides with less than 500 nuclei or $<1$ epithelial cell/HPF $(200 \times)$ were excluded from the study. Positive and negative controls were performed with each test run. The samples were examined at $400 \times$ magnification. A sample was 
considered positive if one or more cells showed red and/ or green fluorescence. The test was negative if no red or green fluorescent cells were detected.

Before immunocytochemistry for CK-20 was performed using the standard streptavidin-biotin peroxidase complex method, selected slides were decolorized with $0.5 \%$ hydrochloric acid in 95\% ethanol. Antigenic epitopes were retrieved by way of a 15 -minute incubation with $2 \%$ 3 -amino-9-ethylcarbazole/1\% hydrogen peroxidase/acetate buffer. The slides were then placed in 3\% hydrogen peroxide/methanol for 20 minutes to block nonspecific background staining due to endogenous peroxidase activity. The primary antibody CK-20 (clone Ks20.8, Neomarkers) was diluted 1:100 and applied to the slides for 30 minutes, followed by a 20-minute incubation in a secondary antibody (goat anti-mouse Ig) solution. Diaminobenzidine served as the chromagen and Mayer's hematoxylin as the counterstain. The whole procedure was performed at room temperature. An overall 5\% of stained cells were set as the threshold for a positive diagnosis.

The immunoreaction was topographically evaluated and scored by the same pathologist. In accordance with previous reports, the CK20 staining pattern was considered normal when an intense reaction was observed in the apical cells, whereas diffuse or absent CK20 immunostaining was considered an abnormal staining pattern.

The analysis of sensitivity, specificity as well as positive and negative predictive values was performed evaluating each test separately and the two and three together. Sensitivity according to tumor grade was carried out for each marker as well as the specificity and they were also evaluated in the control group. Considering the three markers together, the result was considered positive when at least one marker was positively expressed and negative for tumor diagnosis when all the markers were negative.

\section{Results}

Ninety patients included in the study, were diagnosed as either the bladder cancer with primary/recurrent diagnosis or non-neoplastic bladder disease by histopathologic examination. The malignant group consisted of 54 patients (mean age: 66, range 46-80 years) with urothelial carcinoma [LGUC $=31$ patients $(23$ primary $/ 8$ recurrent) and, HGUC $=23$ patients ( 18 primary $/ 5$ recurrent $)]$. The control group consisted of 36 patients (mean age: 49 , range 30-78 years), which were non-neoplastic bladder disease patients with cystitis $(n=9)$, glomerular disease ( $n$ $=6$ ) and as individuals with benign prostatic hyperplasia $(\mathrm{n}=11)$, or patients with a history of prostate cancer $(\mathrm{n}=$ $5)$ and renal cell carcinoma patients $(n=5)$.

The primary interpretation for each cytology case was classified as benign $(n=37)$ or malignant $(n=53)$. "Atypical or suspicious" cases $(\mathrm{n}=14)$ were added to the malignant group. In control group, of the 36 analyses with no tumor present, cytology was negative in 24 patients and, therefore, the specificity was $66.7 \%$ (Table 1). Of the 54 cases in which a tumor was present, cytology were positive in 41 cases, and the sensitivity of cytology was $75.9 \%$. On the other hand; of the 54 cases for which a tumor was present, 45 were positive by $\mathrm{UCyt}^{\mathrm{TM}}{ }^{\mathrm{TM}}$ and the sensitivity was $83.3 \%$ (Table 1). In the control group, 31 were negative by $\mathrm{UCyt}^{\mathrm{TM}}$ and the specificity was $86.1 \%$. Immunocytology with CK20 had a sensitivity of $70.4 \%$ and a specificity of 83.3\% (Table 1).

The results of $\mathrm{UCyt}^{\mathrm{TM}}$ and CK20 expression were compared with urine cytology (Table 1). The sensitivity for the $\mathrm{UCyt}^{\mathrm{Tm}}{ }^{\mathrm{T}}$ test was $83.3 \%$, urine cytology $75.9 \%$ and CK20 $70.3 \%$. The combination of UCyt ${ }^{\mathrm{TM}}$ and cytology, CK20 and cytology, and the three tests together showed sensitivities of $88.9 \%, 77.7 \%$, and $92.5 \%$ respectively.

As reported in Table 2, the sensitivity is higher for $\mathrm{UCyt}^{\mathrm{TM}}$ and cytology than for CK20 in low grade tumors: $77.4 \%$, $67.7 \%$ and $64.5 \%$, respectively (Figure 1 ). In high grade tumors the sensitivity for UCyt $+{ }^{\mathrm{TM}}$ was $91.3 \%, 86.9 \%$ for cytology, and $78.2 \%$ for CK20 (Figure 2). The combination of $\mathrm{UCyt}^{\mathrm{TM}}$ and cytology had higher sensitivity $(83.8 \%)$ than the CK20 and cytology combination (70.9\%). From the simultaneous evaluation of the three tumor markers, $90.3 \%$ of the diagnoses were correct (Table 2).

\section{Discussion}

The urine cytology is a useful test in both diagnosis and follow-up and is highly sensitive for detecting high grade tumors; it is limited because of the decreased sensitivity in detecting low-grade tumors. A recent literature review found that the sensitivity of cytology is between $20 \%$ to $53 \%$, with a mean of $34 \%$; specificity ranges from $83 \%$ to $99.7 \%$, with a mean of $99 \%[17,18]$. Additional screening tests with high sensitivity for tumors of all grades are needed to improve the diagnostic ability of urine cytology and perhaps to reduce the need for frequent cystoscopies, especially in those with low-risk disease.

During the past decade, more than 30 urinary bladder cancer biomarkers have been described [19]. Among these, bladder tumor antigen (BTA Stat and BTA TRAK tests), nuclear matrix protein 22 (NMP-22 enzyme linked immunosorbent assay detection kit) and recently tumorassociated antigens such as M344, 19A211, and LDQ19 (ImmunoCyt fluorescence test), fibrinogen-fibrin degradation products (FDP test), and the UroVysion fluorescent in situ hybridization assay have achieved Food and Drug Administration approval for diagnostic purposes. Still, most of the aforementioned tests are less specific and cost more than conventional cytology [20]. Several large 
Table I: Sensitivity, specificity, and positive (PPV) and negative predictive value (NPV) for cytology, ImmunoCyt/uCyt+, CK20 and combinations.

\begin{tabular}{|c|c|c|c|c|c|c|c|c|c|}
\hline & & BiOPSY & RESULT & & & TEST & RESULT & & \\
\hline & & $\begin{array}{l}\text { LGUC } \\
n=31\end{array}$ & $\begin{array}{c}\text { HGUC } \\
n=23\end{array}$ & Negative & Sensitivity & Specificity & PPV & NPV & OA \\
\hline \multirow{2}{*}{ Cytology } & + & 21 & 20 & 12 & 75.9 & 66.7 & 77.3 & 88.9 & 72.2 \\
\hline & - & 10 & 3 & 24 & & & & & \\
\hline \multirow[t]{2}{*}{ UCyt+ ${ }^{\mathrm{TM}}$} & + & 24 & 21 & 5 & 83.3 & 86.1 & 90.0 & 79.5 & 84.4 \\
\hline & - & 7 & 2 & 31 & & & & & \\
\hline \multirow[t]{2}{*}{ CK20 } & + & 20 & 18 & 6 & 70.4 & 83.3 & 86.3 & 65.2 & 75.5 \\
\hline & - & 11 & 5 & 30 & & & & & \\
\hline \multirow[t]{2}{*}{ Cytology+ UCyt+ ${ }^{\mathrm{TM}}$} & + & 26 & 22 & 5 & 88.9 & 86.1 & 90.5 & 86.1 & 87.7 \\
\hline & - & 5 & 1 & 31 & & & & & \\
\hline \multirow[t]{2}{*}{ Cytology+ CK20 } & + & 22 & 20 & 12 & 77.8 & 66.7 & 77.7 & 66.7 & 73.3 \\
\hline & - & 9 & 3 & 24 & & & & & \\
\hline \multirow[t]{2}{*}{$\mathrm{UCyt}^{\mathrm{TM}}+\mathrm{CK} 2 \mathrm{O}$} & + & 23 & 21 & 7 & 81.5 & 80.5 & 86.3 & 74.3 & 81.1 \\
\hline & - & 8 & 2 & 29 & & & & & \\
\hline \multirow[t]{2}{*}{ Cytology+ UCyt+ ${ }^{T M}+C K 20$} & + & 28 & 22 & 12 & 92.5 & 66.7 & 80.6 & 85.7 & 82.2 \\
\hline & - & 3 & 1 & 24 & & & & & \\
\hline
\end{tabular}

+: Positive test result, -: Negative test result Negative: Negative for malignancy PPV:Positive predictive value NPV: Negative predictive value OA: Overall accuracy

screening studies have demonstrated its low sensitivity and the results of urinary cytology have poor interobserver and intraobserver reproducibility [21].

Halling et al [22] noted that for grade 1, grade 2 and grade 3 bladder tumours, respectively, the grade per grade sensitivity of cytology before 1990 was 37\%, 75\% and 94\% and that it decreased to $11 \%, 31 \%$ and $60 \%$ after 1990 . The suspected reason for the drop in sensitivity is that, before 1990, studies were conducted by pathologists with great expertise in the field of urine cytology, whereas more

Table 2: Comparison of cytology, ImmunoCyt/uCyt+ and CK20 expression for the detection of different grades of bladder cancer

\begin{tabular}{lcccc}
\hline & \multicolumn{4}{c}{ Urothelial tumors } \\
\hline & \multicolumn{3}{c}{ Low grade } & \multicolumn{2}{c}{ High grade } \\
\cline { 2 - 5 } & $\mathrm{n}=31$ & $\%$ & $\mathrm{n}=23$ & $\%$ \\
\hline Cytology & 21 & 67.7 & 20 & 86.9 \\
UCyt+ ${ }^{\mathrm{T} M}$ & 24 & 77.4 & 21 & 91.3 \\
CK20 & 20 & 64.5 & 18 & 78.2 \\
Cytology+UCyt+ $\mathrm{TM}$ & 26 & 83.8 & 22 & 95.6 \\
Cytology+CK20 & 22 & 70.9 & 20 & 86.9 \\
UCyt+TM +CK20 & 23 & 74.1 & 21 & 91.3 \\
Cytology+UCyt+ ${ }^{\mathrm{TM}}+\mathrm{CK} 20$ & 28 & 90.3 & 22 & 95.6 \\
\hline
\end{tabular}

recently, cytology has become one of many tests performed by general pathologists lacking direct expertise in urine cytology. In our institute cytologic examination is performed by a trained cytopathologist.
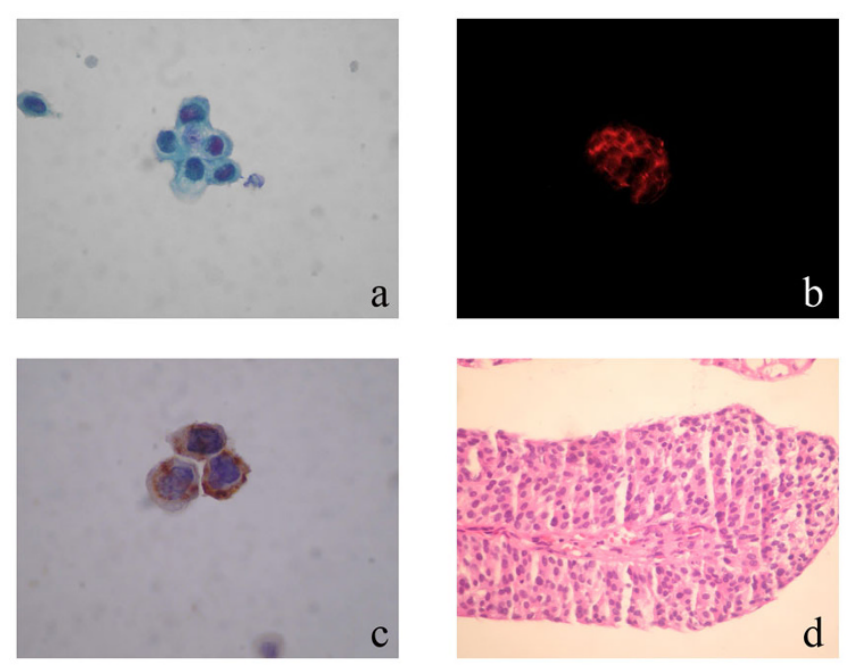

Figure I

[A] Low grade urothelial carcinoma cytology (Papanicolaou stain $\times 200)$, [B] Positive Immunocyt uCyt test (red fluorescence $\times 200),[$ C] CK20 immunocytochemistry $(\times 200)$, [D] Biopsy (HE × 200). 

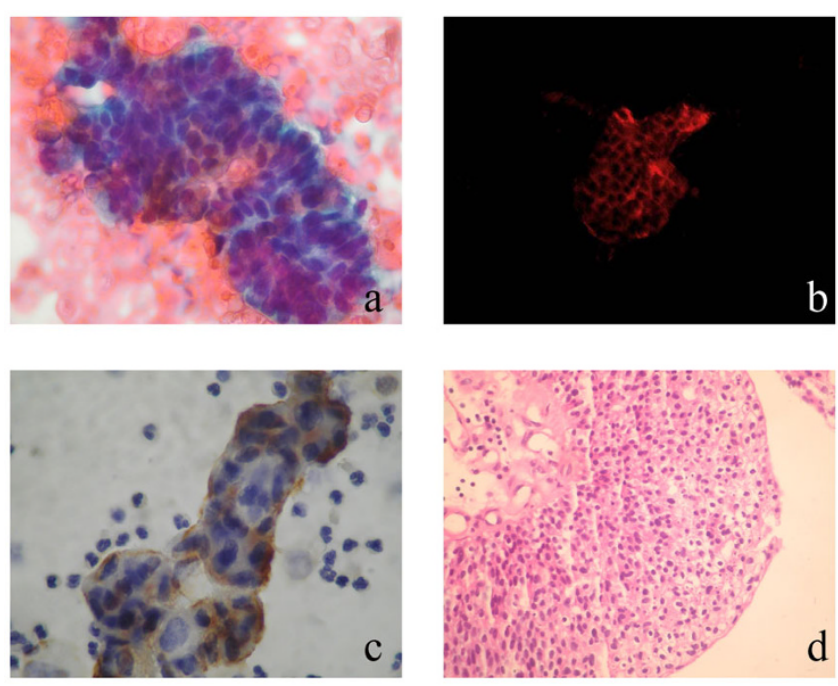

Figure 2

[A] High grade urothelial carcinoma cytology (Papanicolaou stain $\times 200$ ), [B] Positive Immunocyt/ uCyt test (red fluorescence $\times 200),[C]$ CK20 immunocytochemistry $(\times 200)$, [D] Biopsy (HE $\times 200)$.

Unlike other urinary markers, $\mathrm{UCyt}+{ }^{\mathrm{TM}}$ and CK20 are not approved as a stand-alone test but rather, are only approved for use as a surveillance test in conjunction with cytology, which makes direct comparison with other markers more difficult. Overall sensitivity of the combined UCyt $+{ }^{\mathrm{TM}}$ and cytology assay has been reported in the range of $81.0 \%-94.1 \%[23,24]$. Specificity of the combined assay reaches to $61.0 \%-77.7 \%$, which is less than that offered by cytology alone [24,25]. In our study the sensitivity for cytology is $75.9 \%$ and for UCyt $+{ }^{\mathrm{TM}}$ is $83.3 \%$ and for combination of the both tests are $88.9 \%$. In low grade tumors the sensitivity for $\mathrm{UCyt}+{ }^{\mathrm{TM}}(77.4 \%)$ is more than for cytology $(67.7 \%)$ and for the combination of both tests $(83.8 \%)$. On the other hand the specificity for cytology $(66.7 \%)$ reached $86.1 \%$ for the combination of the two tests (Table 1 ). These results are in parallel with most of the reports $[11,24]$.

In our study the CK20 sensitivity is $70.4 \%$ and less than for cytology and UCyt $+{ }^{\mathrm{TM}}$, but reached $77.8 \%$ when combined with urine cytology. Some authors reported sensitivity for CK20 between $86 \%$ and $91 \%$ with a specificity between $67 \%$ and $96 \%$ even if in most of the cases the specificity was tested in healthy controls and not in urine from cases of chronic inflammation $[25,26]$. In these series strong correlation was found between tumor grade and CK20 expression in urine. The sensitivity was higher for CK20 than urine cytology. According to a recently published article the sensitivity of CK20 mRNA was 100\% in detecting grade 1 tumors, whereas the sensitivity for high grade (III) was $84.3 \%$. This suggests that CK20 mRNA is a potential tumor marker for the early detection of bladder cancer [27]. In our study we could not find any relation between tumor grade and CK20 expression.

Cytology and cystoscopy have been used as detection tests for patients suspicious for bladder cancer or for the surveillance of patients at risk of tumor recurrence. Cystoscopy is highly sensitive for most tumors but has some practical limitations. It may fail to identify smaller, flat tumors such as carcinoma in situ. Also, despite the technical advances in cystoscopes, the procedure is often perceived as invasive and a source of patient anxiety [28]. There is also a significant financial cost related to frequent cystoscopic monitoring, in terms of health care resources and patient time. Conversely, urinary cytology is noninvasive and highly specific but has poor sensitivity for lowgrade, well-differentiated lesions. Thus it cannot be used to replace cystocopy and is used, rather, as an adjunct to help detect occult tumors. Additional screening tests with high sensitivity and specificity for urothelial tumors of all grades are indicated to help improve the diagnostic ability of urine cytology as well as to reduce the need for frequent cystoscopies, especially in those with low-risk disease.

The ImmunoCyt/uCyt+ assay require technical expertise, extensive sample handling and preparation and specialized equipment. However, a person with minimal cytology training and experience can perform the test. The CK20 immunostaining can be used routinely but needs some additional work performed by the technician (bleaching of slides etc).

\section{Conclusion}

In conclusion, combined use of $\mathrm{UCyt}+{ }^{\mathrm{TM}}$ and cytology can improve the sensitivity and specificity over the CK20 and cytology combination for the detection of bladder cancer in urine. Further new studies with larger patient populations should be done in order to assess the effectiveness of these tests to replace conventional cystoscopy in the primary diagnosis.

\section{Competing interests}

The authors declare that they have no competing interests.

\section{Authors' contributions}

IS participated in the study design, collection of the background references, photomicrography of the immunocytochemical results, displaying the results of the study, writing the discussion of the results, carried out the sequence alignment and drafted the manuscript. FT and FO conceived and designed the study, gave and reviewed the final histopathological diagnosis, and revised the manuscript for important intellectual content. MS, and SS conducted the clinical part of the study and were involved in the design and coordination of the study and drafting the manuscript. All authors read and approved the final manuscript. 


\section{References}

I. Bohle A, Balck F, von Weitersheim J, Jocham D: The quality of life during intravesical bacillus Calmette-Guerin therapy. J Urol 1996, I55(4): I 221-6.

2. Rübben H, Lutzeyer W, Fischer N, Deutz F, Lagrange W, Giani G: Natural history and treatment of low and high risk superficial bladder tumors. J Urol 1988, 139:283-5.

3. Millán-Rodríguez F, Chéchile-Toniolo G, Salvador-Bayarri J, Palou J, Algaba F, Vicente-Rodríguez J: Primary superficial bladder cancer risk groups according to progression, mortality and recurrence. J Urol 2000, 164:680-4.

4. Schroeder GL, Lorenzo-Gomez MF, Hautmann SH, Friedrich MG, Ekici S, Huland H, Lokeshwar V: A side by side comparison of cytology and biomarkers for bladder cancer detection. J Urol 2004, I72: I I23-6.

5. Grossman HB, Messing E, Soloway M, Tomera K, Katz G, Berger Y, Shen $Y$ : Detection of bladder cancer using apoint-of-care proteomic assay. JAMA 2005, 293:810-6.

6. Hautmann S, Toma M, Lorenzo Gomez MF, Friedrich MG, Jaekel T, Michl U, Schroeder GL, Huland H, Juenemann KP, Lokeshwar VB: Immunocyt and the HA-HAase urine tests for the detection of bladder cancer: a side-by-side comparison. Eur Urol 2004, 46:466-7I.

7. Krause FS, Rauch A, Schrott KM, Engehausen DG: Clinical decisions for treatment of different staged bladder cancer based on multitarget fluorescence in situ hybridization assays? World J Urol 2006, 24:418-22.

8. Lodde M, Mian C, Comploj E, Palermo S, Longhi E, Marberger M, Pycha A: uCyt+ test: alternative to cystoscopy for less-invasive follow-up of patients with low risk of urothelial carcinoma. Urology 2006, 67:950-4.

9. Mian C, Maier K, Comploj E, Lodde M, Berner L, Lusuardi L, Palermo $\mathrm{S}$, Vittadello F, Pycha A: uCyt+/ImmunoCyt in the detection of recurrent urothelial carcinoma: an update on 1991 analyses. Cancer 2006, 108:60-5.

10. Têtu B, Tiguert R, Harel F, Fradet Y: ImmunoCyt/uCyt+ improves the sensitivity of urine cytology in patients followed for urothelial carcinoma. Mod Pathol 2005, I 8:83-9.

II. Toma MI, Friedrich MG, Hautmann SH, Jäkel KT, Erbersdobler A, Hellstern A, Huland H: Comparison of the ImmunoCyt test and urinary cytology with other urine tests in the detection and surveillance of bladder cancer. World J Urol 2004, 22: I45-9.

12. Allard $P$, Fradet $Y$, Têtu B, Bernard $P$ : Tumor associated antigens as prognostic factors for recurrence in $\mathbf{3 8 2}$ patients with primary transitional cell carcinoma of the bladder. Clin Cancer Res 1995, I: I 195-1202.

13. Fradet Y, Lockhard C: Performance characteristics of a new monoclonal antibody test for bladder cancer: ImmunoCyt trade mark. Can J Urol 1997, 4:400-5.

14. Miettinen M: Keratin 20: immunohistochemical marker for gastrointestinal, urothelial, and merkel cell carcinomas. Mod Pathol 1995, 8(4):384-8.

15. Sauter G, Knowles MA, Hartmann A: Tumours of the urinary system. In World Health Organization Classification of Tumours. Pathology and Genetics of Tumours of the Urinary System and Male Genital Organs Edited by: Eble JN, Sauter G, Epstein JI, Sesterhenn IA. Lyon: IARC Press; 2004: 110

16. Murphy WM, Soloway MS, Jukkola AF, Crabtree WN, Ford KS: Urinary cytology and bladder cancer. The cellular features of transitional cell neoplasms. Cancer 1984, 53:| I555-|565.

17. Lotan Y, Roehrborn CG: Cost effectiveness of a modified care protocol substituting bladder tumor markers for cystoscopy for the follow up of patients with transitional cell carcinoma of the bladder: a decision analytical approach. J Urol 2002, 1 67:75-79.

18. Bastacky S, Ibrahim S, Wilczynski SP, Murphy WM: The accuracy of urinary cytology in daily practice. Cancer 1999, 87: I I8-128.

19. Sanchez-Carbayo M: Recent advances in bladder cancer diagnostics. Clin Biochem 2004, 37:562-57I.

20. Simon MA, Lokeshwar VB, Soloway MS: Current bladder cancer tests: unnecessary or beneficial? Crit Rev Oncol Hematol 2003, 47:91-107.

21. Sánchez-Carbayo M, Urrutia M, Silva JM, Romaní R, García J, Alférez F, González deBuitrago JM, Navajo JA: Urinary tissue polypeptidespecific antigen for the diagnosis of bladder cancer. Urology 2000, 55(4):526-32.
22. Halling KC, King W, Sokolova IA, Meyer RG, Burkhardt HM, Halling AC, Cheville JC, Sebo TJ, Ramakumar S, Stewart CS, Pankratz S, O'Kane DJ, Seelig SA, Lieber MM, Jenkins RB: A comparison of cytology and fluorescence in situ hybridization for the detection of urothelial carcinoma. J Urol 2000, I64:| 768-75.

23. Lodde M, Mian C, Negri G, Berner L, Maffei N, Lusuardi L, Palermo S, Marberger M, Brssner C, Pycha A: Role of uCyt-in the detection and surveillance of urothelial carcinoma. Urology 2003, 6 I:243-247.

24. Messing EM, Teot L, Korman H, Underhill E, Barker E, Stork B, Qian J, Bostwick DG: Performance of urine test in patients monitored for recurrence of bladder cancer: a multicenter study in the United States. J Urol 2005, I 74: I 238-I 24I.

25. Rotem D, Cassel A, Lindenfeld N, Mecz Y, Sova Y, Resnick M, Stein A: Urinary cytokeratin $\mathbf{2 0}$ as a marker for transitional cell carcinoma. Eur Urol 2000, 37(5):60l-4.

26. Buchumensky V, Klein A, Zemer R, Kessler OJ, Zimlichman S, Nissenkorn I: Cytokeratin 20: a new marker for early detection of bladder cell carcinoma? J Urol 1998, I60(6 Pt I): | 97|-4.

27. Eissa S, Zohny SF, Swellam M, Mahmoud MH, El-Zayat TM, Salem AM: Comparison of CD44 and cytokeratin 20 mRNA in voided urine samples as diagnostic tools for bladder cancer. Clinical Biochemistry 2008, 41: I335-1341.

28. Lotan Y, Svatek RS, Sagalowsky Al: Should we screen for bladder cancer in a highrisk population? A cost per life-year saved analysis. Cancer 2006, 107:982-90.
Publish with Bio Med Central and every scientist can read your work free of charge

"BioMed Central will be the most significant development for disseminating the results of biomedical research in our lifetime. "

Sir Paul Nurse, Cancer Research UK

Your research papers will be:

- available free of charge to the entire biomedical community

- peer reviewed and published immediately upon acceptance

- cited in PubMed and archived on PubMed Central

- yours - you keep the copyright

Submit your manuscript here:

http://www.biomedcentral.com/info/publishing_adv.asp
BioMedcentral 